\title{
Acta
Biochimica
Polonica
}

Vol. 51 No. 3/2004

$649-663$

QUARTERLY

\section{Kinetics and specificity of guinea pig liver aldehyde oxidase and bovine milk xanthine oxidase towards substituted benzaldehydes}

\author{
Georgios I. Panoutsopoulos ${ }^{1,2 \bowtie}$ and Christine Beedham ${ }^{1}$ \\ ${ }^{1}$ Department of Pharmaceutical Chemistry, School of Pharmacy, University of Bradford, \\ Bradford, U.K., and ${ }^{2}$ Department of Experimental Pharmacology, Medical School, Athens \\ University, Athens, Greece
}

Received: 09 July, 2003; revised: 26 February, 2004; accepted: 25 March, 2004

Key words: aldehyde oxidase, benzaldehydes, dopamine, isovanillin, protocatechuic aldehyde, xanthine oxidase

\begin{abstract}
Molybdenum-containing enzymes, aldehyde oxidase and xanthine oxidase, are important in the oxidation of N-heterocyclic xenobiotics. However, the role of these enzymes in the oxidation of drug-derived aldehydes has not been established.

The present investigation describes the interaction of eleven structurally related benzaldehydes with guinea pig liver aldehyde oxidase and bovine milk xanthine oxidase, since they have similar substrate specificity to human molybdenum hydroxylases. The compounds under test included mono-hydroxy and mono-methoxy benzaldehydes as well as 3,4-dihydroxy-, 3-hydroxy-4-methoxy-, 4-hydroxy-3-methoxy-, and 3,4-dimethoxy-benzaldehydes. In addition, various amines and catechols were tested with the molybdenum hydroxylases as inhibitors of benzaldehyde oxidation.

The kinetic constants have shown that hydroxy-, and methoxy-benzaldehydes are excellent substrates for aldehyde oxidase $\left(K_{\mathrm{m}}\right.$ values $5 \times 10^{-6} \mathrm{M}$ to $\left.1 \times 10^{-5} \mathrm{M}\right)$ with lower affinities for xanthine oxidase $\left(K_{\mathrm{m}}\right.$ values around $\left.10^{-4} \mathrm{M}\right)$. Therefore, aldehyde oxidase activity may be a significant factor in the oxidation of the aromatic aldehydes generated from amines and alkyl benzenes during drug metabolism. Compounds with a 3 -methoxy group showed relatively high $V_{\max }$ values with aldehyde oxidase, whereas the presence of a 3-hydroxy group resulted in minimal $V_{\max }$ values or no reaction. In addition, amines acted as weak inhibitors, whereas catechols had a more pronounced inhibitory effect on the aldehyde oxidase activity. It is therefore possible that aldehyde oxidase may be critical in the oxidation of the analogous phenylacetaldehydes derived from dopamine and noradrenaline.
\end{abstract}

\footnotetext{
${ }^{\square}$ Address for correspondence: Georgios I. Panoutsopoulos, 5 Tenedou Street, Platia Amerikis, Athens 112 57, Greece; tel.: (302 10) 864 9617; fax: (302 10) 746 2554; e-mail: geopanou@otenet.gr and gpanouts@bio.uth.gr
} 
Aldehydes are widely distributed in nature. They constitute a group of relatively reactive organic compounds which occur as natural constituents in a wide variety of foods. More than 300 aldehydes have been identified in foods and food components and are widely used as flavouring agents (Feron et al., 1991; Lindahl, 1992).

Most aldehydes are irritants producing tissue damage at the site of application, and many possess genotoxic activity (Dellarco, 1988; Ma \& Harris, 1988). Some aldehydes are potentially carcinogenic in several animal species, whereas others have limited or no carcinogenicity (Feron et al., 1991).

Although aldehydes are not typically found in any measurable concentration in cells, many compounds (these include alcohols, amines and hydrocarbons) are ultimately converted, via an aldehyde intermediate, to the corresponding acid.

Even though only a few drugs contain aldehyde groups in their structures, there are many drugs with an amino group attached to an unsubstituted methylene carbon which can be transformed into aldehydes via the action of monoamine oxidase. Exposure to exogenous aldehydes can also occur through the ingestion of metabolic precursors such as primary alcohols. Another common source of an aldehydic group is the hydroxylation of an aromatic methyl group to an alcohol, which subsequently undergoes oxidation, such as the oral hypoglycaemic agent tolbutamide, which is used for the treatment of diabetes mellitus (Washio et al., 1993).

Aldehydes are also produced in the body via oxidative deamination of compounds such as biogenic amines, catalyzed by the action of monoamine oxidase. For example, homovanillamine is deaminated to homovanillyl aldehyde (Beedham et al., 1995b). In addition, nearly all of the common $\alpha$-amino acids are converted to reactive aldehydes by the enzyme myeloperoxidase (Hazen et al., 1998).

Biogenic and xenobiotic aldehydes can either be oxidized to the corresponding acids, which may be catalysed by aldehyde dehydrogenase (EC 1.2.1.3, aldehyde: $\mathrm{NAD}^{+}$oxidoreductase), aldehyde oxidase (EC 1.2.3.1, aldehyde:oxygen oxidoreductase) and/or xanthine oxidase (EC 1.2.3.2, xanthine:oxygen oxidoreductase), or reduced by aldehyde reductase and/or alcohol dehydrogenase to the corresponding alcohols (Fig. 1). Although some aldehydes may be reduced to alcohols in vivo, the main metabolic routes are conversion to acids.

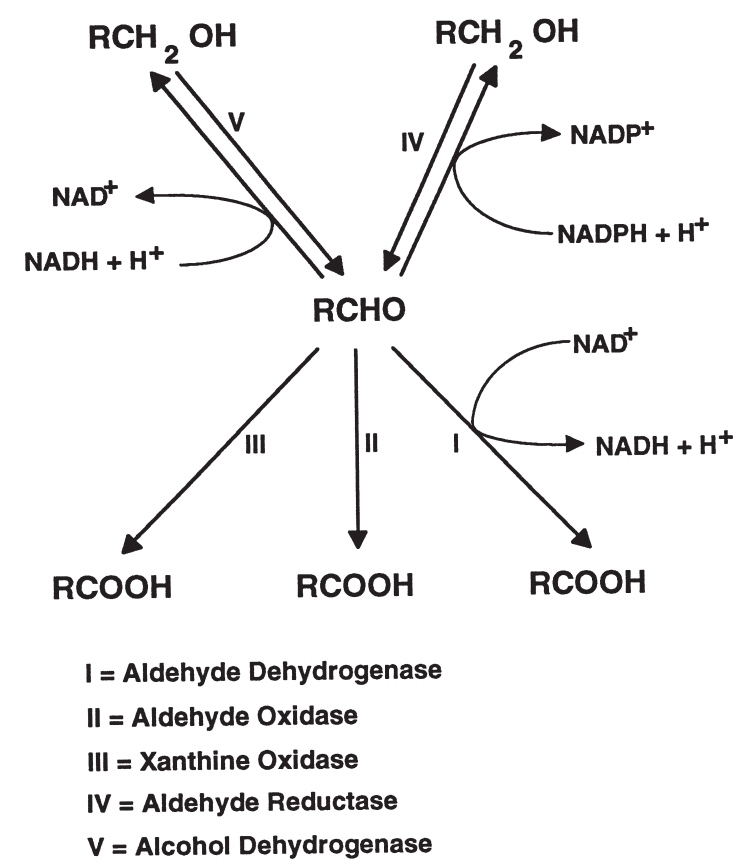

Figure 1. The pathways of aldehyde metabolism.

The molybdenum hydroxylases aldehyde oxidase and xanthine oxidase catalyse the oxidation of a wide range of N-heterocycles and aldehydes (Krenitsky et al., 1972; Beedham, 1985; Beedham et al., 1995a). Most of the reports in the literature have utilized heterocycles as substrates rather than aldehydes and many studies have been carried out with rabbit liver aldehyde oxidase, which has different properties than human liver aldehyde oxidase (Johns, 1967; Beedham, 1987). Aldehyde oxidase activity is predominant in the liver (Sasaki et al., 1983; Beedham et al., 1987), whereas xanthine oxidase activity is present at high levels in the lactating 
mammary gland (Bruder et al., 1982) and primarily in cow's milk but not in human milk (Modi et al., 1959). Although these enzymes are similar in structure and molecular properties, they differ in substrate specificity (Krenitsky et al., 1972). While the substrate specificity towards aromatic heterocycles has been extensively investigated, very few systematic studies on the enzymatic oxidation of aldehydes are found in the literature (Booth, 1938; Gordon et al., 1940; Pelsy \& Klibanov, 1983).

The present study examines the interaction of eleven structurally related benzaldehydes with guinea pig liver aldehyde oxidase and bovine milk xanthine oxidase, as these enzymes have similar substrate specificity to human molybdenum hydroxylases (Beedham et al., 1987a; Critchley, 1989). The compounds under test included mono-hydroxy-, and monomethoxy-benzaldehydes, as well as 3,4-dihydroxy-, 3-hydroxy-4-methoxy-, 4-hydroxy-3-methoxy-, and 3,4-dimethoxy-benzaldehydes. In addition, a number of amines and catechols were tested with guinea pig liver aldehyde oxidase as inhibitors of benzaldehyde oxidation.

\section{MATERIALS AND METHODS}

Animals. The animals used in this study were Dunkin-Hartley guinea pigs (450$950 \mathrm{~g})$. They were fed with FD1 pellets supplemented with ascorbic acid and received hay three times weekly. All animals were allowed food and water ad libitum and maintained in a strictly controlled temperature; $18 \pm 1^{\circ} \mathrm{C}$. Humidity was kept at $50 \%$ and the lighting cycle was $07.00-19.00 \mathrm{~h}$ light and 19.00-07.00 h dark.

Chemicals. 4-Hydroxy-3-methoxybenzaldehyde (vanillin), 3,4-dihydroxybenzaldehyde (protocatechuic aldehyde), 3-hydroxy-4-methoxybenzaldehyde (isovanillin), 3-methoxybenzaldehyde (3-anisaldehyde), 2-phenylethylamine hydrochloride, 3,4-dimethoxy-2-phenyl- ethylamine (homoveratrylamine), 3,4-dihydroxyphenylethylamine (dopamine), 3,4-dihydroxyphenylethanolamine (noradrenaline), L-3,4-dihydroxyphenylalanine (L-DOPA) and 3,4-dihydroxyphenylacetic acid (DOPAC) were supplied from Sigma Chemical Company Ltd. Benzaldehyde, 2-hydroxybenzaldehyde (salicylaldehyde), 3,4-dimethoxybenzaldehyde, 4-hydroxybenzaldehyde, 2-methoxybenzaldehyde (2-anisaldehyde), 4-methoxybenzaldehyde (4-anisaldehyde), phthalazine, 4-hydroxy-3-methoxy-2-phenylethylamine (homovanillamine), and phenanthridine were purchased from Aldrich Chemical Co. Ltd. 3-Hydroxybenzaldehyde was from Ralph Emanuel, 1,2-dihydroxybenzene (catechol) from BDH Chemicals Ltd, xanthine (pure) from Koch-Light Laboratories Ltd, Coomassie Blue G-250 from Pierce, and 2-methylphthalaziniun iodide was synthesized according to procedures of Smith \& Otremba (1962).

Enzymes. Xanthine oxidase (grade I) was obtained from Sigma Chemical Company Ltd: from bovine buttermilk (EC 1.2.3.22), 0.47 units/g protein, $38 \mathrm{mg}$ protein/ml (biuret).

Preparation of partially purified aldehyde oxidase from guinea pig liver. Guinea pigs were killed by cervical dislocation and their livers were placed in 3-4 volumes of ice-cold isotonic potassium chloride solution $(1.15 \%$ $\mathrm{KCl}, \mathrm{w} / \mathrm{v})$. They were then homogenized on ice in a homogenizer fitted with a Teflon pestle.

The homogenate was heated at $55-57^{\circ} \mathrm{C}$ for $11 \mathrm{~min}$ and then centrifuged at $15000 \times \boldsymbol{g}$ for $45 \mathrm{~min}$ at $4^{\circ} \mathrm{C}$. The resulting clear red supernatant was filtered through glass wool and then solid ammonium sulphate was added to give $50 \%$ saturated solution (35.3 $\mathrm{g} / 100 \mathrm{ml}$ at $4^{\circ} \mathrm{C}$ ).

The resulting suspension was centrifuged at $6000 \times \mathbf{g}$ for $20 \mathrm{~min}$ at $4^{\circ} \mathrm{C}$ and the precipitate re-dissolved in $5 \mathrm{ml}$ of $1 \mathrm{mM}$ EDTA per animal liver. The enzyme was stored in liquid nitrogen in the form of small beads until needed. 
Spectrophotometric determination of enzyme activity. All kinetic measurements and UV spectra were determined using a Pye-Unicam SP8-250 UV/Visible Spectrophotometer fitted with a Pye-Unicam cell temperature controller at $37^{\circ} \mathrm{C}$.

Aldehyde oxidase activity was routinely estimated using potassiun ferricyanide $(1 \mathrm{mM})$ as the electron acceptor, at $420 \mathrm{~nm}$, using a heterocyclic substrate such as phthalazine. Xanthine oxidase activity was checked with xanthine, at $295 \mathrm{~nm}$, and molecular oxygen as the electron acceptor.

Protein content estimation in aldehyde oxidase. The protein content in aldehyde oxidase was determined using Coomassie Blue dye reagent and bovine serum albumin as the standard, measured at $595 \mathrm{~nm}$, according to the method of Bradford (1976).

Determination of kinetic constants for aldehyde oxidase. Kinetic constants were determined using aldehyde oxidase which was prepared from three animal livers. All assays were carried out in $67 \mathrm{mM}$ Sörensen's phosphate buffer, $\mathrm{pH}$ 7.0, containing $0.1 \mathrm{mM}$ EDTA, varying concentrations of substrate, potassium ferricyanide ( $1 \mathrm{mM})$, in a final volume of $3 \mathrm{ml}$ and sufficient enzyme to produce measurable rates over the range of substrate concentrations under study.

Michaelis-Menten constants were determined by measuring the initial oxidation rates from a minimum ten different substrate concentrations over the first $2-5 \mathrm{~min}$, following spectrophotometrically the decrease in absorbance at $420 \mathrm{~nm}$. All aldehydes were initially tested for non-enzymatic oxidation and/or interaction with potassium ferricyanide.

Since many of the benzaldehydes interacted with potassium ferricyanide, the oxidation rates of these substrates were monitored directly. This was achieved by determining the UV spectra of aldehydes and their acid products, which were scanned individually in the range between 200-400 $\mathrm{nm}$. Absorbance maxima were chosen in the UV spectrum of the aldehydes, at which wavelength the corresponding acid had minimal absorbance at a similar concentration. The molar absorption of each aldehyde was calculated at the specified wavelength.

The wavelengths chosen for measurement of the initial oxidation rates for each aldehyde, using molecular oxygen as the electron acceptor, and the corresponding molar absorption are presented in Table 1.

Therefore, the oxidation rates of benzaldehydes were measured at the chosen wavelength under similar conditions as with potassium ferricyanide assay. All initial rates measured were found to be linear over the first 2-3 min of reaction.

Assays were validated by incubating each aldehyde with aldehyde oxidase and scanning the resultant UV spectrum from 200-400 nm at various time intervals until acid formation was maximal. In each case the final UV spectra corresponded to that of the acid. This is illustrated in Fig. 2 for 3-methoxybenzaldehyde.

The Michaelis-Menten constant $\left(K_{\mathrm{m}}\right)$ and maximum velocity $\left(V_{\max }\right)$ were determined from the 'Lineweaver-Burk' plot of $1 / V$ versus $1 /[\mathrm{S}]$. The line of the best fit through the points was calculated using simple linear regression by the least squares method. The 'coefficient of determination' was used to express the goodness of fit of the line. The substrate efficiency $\left(K_{\mathrm{s}}\right)$, was calculated from the formula: $K_{\mathrm{s}}=V_{\max } / K_{\mathrm{m}}$.

Determination of kinetic constants for xanthine oxidase. The rates of aldehyde oxidation by xanthine oxidase were measured with molecular oxygen as electron acceptor and at the same wavelengths as for aldehyde oxidase.

Determination of the mode of inhibition and inhibitor constants for molybdenum hydroxylase inhibitors. The effect of inhibitors upon the oxidation rate of a substrate was also investigated spectrophotometrically. Compounds which showed no reaction as substrates by aldehyde oxidase were tested as in- 
Table 1. Wavelengths and molar absorption used for the measurement of the enzymatic oxidation of substituted benzaldehydes.

\begin{tabular}{lll}
\hline Substrate & $\begin{array}{l}\text { Wavelength } \\
(\mathrm{nm})\end{array}$ & $\begin{array}{l}\text { Molar absorption, } \varepsilon \\
\left(\mathrm{M}^{-1} \mathrm{~cm}^{-1}\right)\end{array}$ \\
\hline Benzaldehyde & 249 & 10083 \\
2-Hydroxybenzaldehyde & 255 & 9728 \\
3-Hydroxybenzaldehyde & 255 & 9813 \\
4-Hydroxybenzaldehyde & 290 & 12917 \\
2-Methoxybenzaldehyde & 256 & 11042 \\
3-Methoxybenzaldehyde & 256 & 10313 \\
4-Methoxybenzaldehyde & 284 & 17130 \\
3,4-Dihydroxybenzaldehyde & 330 & 8499 \\
3-Hydroxy-4-methoxybenzaldehyde & 230 & 6500 \\
4-Hydroxy-3-methoxybenzaldehyde & 310 & 8854 \\
3,4-Dimethoxybenzaldehyde & 310 & 9333 \\
\hline
\end{tabular}

UV spectra of aldehydes and their acid products were scanned individually in the range of 200-400 $\mathrm{nm}$. The absorbance maxima were chosen in the UV spectrum of the aldehydes, at which wavelength the corresponding acid had minimal absorbance at a similar concentration.

hibitors of benzaldehyde or 2-hydroxybenzaldehyde oxidation. The rate of oxidation of at least ten varying concentrations of 2-hydroxybenzaldehyde was monitored in the

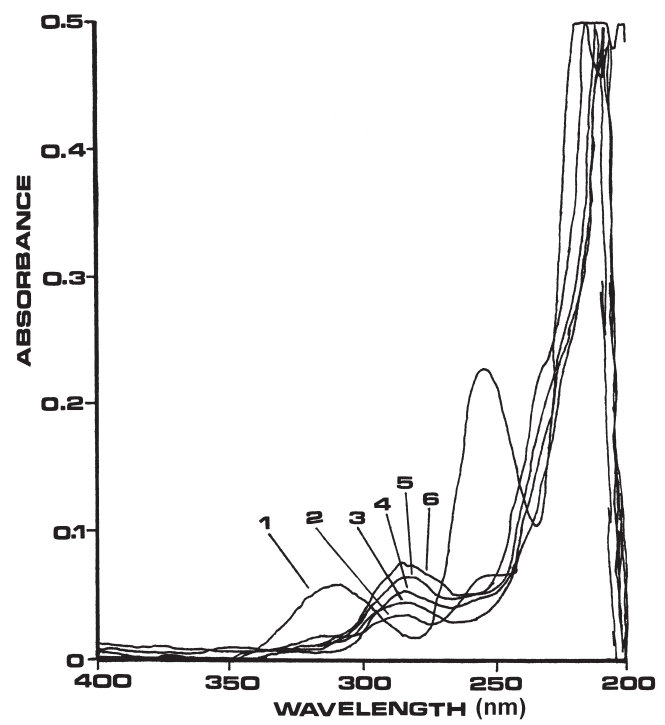

Figure 2. UV spectra of oxidation of 3-methoxybenzaldehyde by aldehyde oxidase at consecutive time intervals.

3-Methoxybenzaldehyde (0.024 $\mathrm{mM})$ was incubated with $0.015 \mathrm{ml}$ aldehyde oxidase $(18.6 \mathrm{mg} / \mathrm{ml})$ in $3 \mathrm{ml}$ 67 mM Sörensen's phosphate buffer, pH 7.0, containing $0.1 \mathrm{mM}$ EDTA, at consecutive time intervals (1, absence of enzyme; 2, $0 \mathrm{~min} ; 3,5 \mathrm{~min} ; 4,10 \mathrm{~min} ; 5,15$ $\min ; 6,20 \mathrm{~min})$. presence or absence of two concentrations of an inhibitor, [I].

The type of inhibition was determined by examination of double reciprocal plots of both non-inhibited and inhibited reactions and the inhibitor constant $\left(K_{\mathrm{i}}\right)$ was calculated by the use of information derived from these plots.

\section{RESULTS AND DISCUSSION}

\section{Kinetic constants for the oxidation of sub- stituted benzaldehydes by guinea pig liver aldehyde oxidase}

The $K_{\mathrm{m}}, V_{\max }$ and $K_{\mathrm{s}}$ values calculated for aldehyde oxidase with the heterocyclic substrate phthalazine, using ferricyanide as an electron acceptor, were found to be 0.089 $\mathrm{mM}, 0.44 \mu \mathrm{mol} / \mathrm{min}$ per $\mathrm{mg}$ protein and 5.0 $\mathrm{ml} / \mathrm{min}$ per $\mathrm{mg}$ protein, respectively. These kinetic constants are similar to those reported previously for phthalazine (Beedham et al., 1990; Critchley et al., 1992).

All kinetic plots showed substrate inhibition at concentrations of around $10 \times K_{\mathrm{m}}$ value. Substrate inhibition was also noticed in the oxidation of 2-hydroxybenzaldehyde $(50 \times$ 
$K_{\mathrm{m}}$ value) with rabbit liver aldehyde oxidase (Rajagopalan \& Handler, 1964) and 4-hydroxy-3-methoxybenzaldehyde at concentrations greater than $5 \mathrm{mM}$ with aldehyde oxidase from Streptomyces viridosporus T7A (Wilkof et al., 1984). However, this phenomenon is not only restricted to aldehydes, but also to uncharged substrates such as phthalazine (Coughlan, 1980) and quinoline which exhibit marked substrate inhibition (Rajagopalan \& Handler, 1964). Excess substrate may cause an over reduction of Mo(III) which results in a slower reoxidation to Mo(VI) (Coughlan, 1980). In contrast, quaternary substrates such as $N$-methylquinolinium and $\mathrm{N}$-ethylquinolinium do not show substrate inhibition with aldehyde oxidase (Taylor et al., 1984).

Most of the substituted benzaldehydes were found to be excellent substrates of hepatic guinea pig aldehyde oxidase (Table 2). The lowest $K_{\mathrm{m}}$ values were obtained with 2-methoxy-, 3-hydroxy-, and 4-hydroxy-benzaldehydes and the best substrate for guinea pig alde- hyde oxidase, in terms of substrate efficiency $\left(K_{\mathrm{S}}\right)$, is 2-methoxybenzaldehyde. Relatively low $V_{\max }$ values were obtained with 3 -hydroxy-, and 4-hydroxy-benzaldehydes.

Benzaldehyde oxidation has also been studied with human liver aldehyde oxidase (Johns, 1967) under similar conditions to those employed in the present study. Johns found the $K_{\mathrm{m}}$ for the human liver enzyme to be of the same order as the $K_{\mathrm{m}}$ value reported here for guinea pig liver aldehyde oxidase. This is further evidence of the similarity in substrate specificity between guinea pig and human liver aldehyde oxidase (Krenitsky et al., 1986; Beedham et al., 1987a). Although absolute oxidation rates were not reported by Johns (1967), benzaldehyde had higher reaction velocities than the aliphatic aldehydes tested as substrates for the human liver aldehyde oxidase.

4-Hydroxy-3-methoxybenzaldehyde was found to be an excellent substrate for guinea pig liver aldehyde oxidase with $K_{\mathrm{m}}$ value (Table 2) similar to that reported by Wilkof et al.

Table 2. Kinetic constants for the oxidation of substituted benzaldehydes by guinea pig liver aldehyde oxidase.

\begin{tabular}{|c|c|c|c|c|c|}
\hline $\mathrm{R}_{2}$ & $\begin{array}{c}\text { Substituent } \\
\mathrm{R}_{3}\end{array}$ & $\mathrm{R}_{4}$ & $\begin{array}{l}K_{\mathrm{m}}^{*} \\
(\mathrm{mM})\end{array}$ & $\begin{array}{l}V_{\max } \\
(\mu \mathrm{mol} / \mathrm{min} \text { per } \mathrm{mg})\end{array}$ & $\begin{array}{l}K_{\mathrm{s}}=\left(V_{\mathrm{max}} / K_{\mathrm{m}}\right) \\
(\mathrm{ml} / \mathrm{min} \text { per } \mathrm{mg})\end{array}$ \\
\hline $\mathrm{H}$ & $\mathrm{H}$ & $\mathrm{H}$ & 0.019 & 0.34 & 18 \\
\hline $\mathrm{OH}$ & $\mathrm{H}$ & $\mathrm{H}$ & 0.02 & 0.30 & 15 \\
\hline $\mathrm{H}$ & $\mathrm{OH}$ & $\mathrm{H}$ & 0.005 & 0.05 & 10 \\
\hline $\mathrm{H}$ & $\mathrm{H}$ & $\mathrm{OH}$ & 0.008 & 0.12 & 15 \\
\hline $\mathrm{OCH}_{3}$ & $\mathrm{H}$ & $\mathrm{H}$ & 0.004 & 0.33 & 73 \\
\hline $\mathrm{H}$ & $\mathrm{OCH}_{3}$ & $\mathrm{H}$ & 0.02 & 0.38 & 19 \\
\hline $\mathrm{H}$ & $\mathrm{H}$ & $\mathrm{OCH}_{3}$ & 0.013 & 0.28 & 22 \\
\hline $\mathrm{H}$ & $\mathrm{OH}$ & $\mathrm{OH}$ & $\mathrm{I}^{* *}$ & & \\
\hline $\mathrm{H}$ & $\mathrm{OH}$ & $\mathrm{OCH}_{3}$ & $I^{* *}$ & & \\
\hline $\mathrm{H}$ & $\mathrm{OCH}_{3}$ & $\mathrm{OH}$ & 0.029 & 0.45 & 17 \\
\hline $\mathrm{H}$ & $\mathrm{OCH}_{3}$ & $\mathrm{OCH}_{3}$ & 0.019 & 0.38 & 21 \\
\hline
\end{tabular}

The oxidation rates of the substituted benzaldehydes by aldehyde oxidase were measured spectrophotometrically at $37^{\circ} \mathrm{C}$ with molecular oxygen as an acceptor. For details see Materials and Methods. All correlation coefficients $(r)>0.998 ;{ }^{*} \mathrm{n}=2{ }^{* *} \mathrm{I}=\mathrm{in}-$ hibitor. 
(1984) for both soluble and immobilised aldehyde oxidase prepared from $S$. viridosporus T7A. 4-Hydroxy-3-methoxybenzaldehyde has also been used to study species variation of aldehyde oxidase occurrence in 79 species. Wurzinger \& Hartestein (1974) found 4-hydroxy-3-methoxybenzaldehyde to be a substrate of aldehyde oxidase from mollusks, crustaceans and insects. Aldehyde oxidase activity was not found in birds, but it was observed in four other classes of vertebrates: osteichthyes, amphibia, reptilia and mammalia (Sprague-Dawley rat liver and DBA mouse liver).

The $K_{\mathrm{m}}$ value obtained for 2-hydroxybenzaldehyde with guinea pig hepatic aldehyde oxidase is markedly lower than the $K_{\mathrm{m}}$ value of $0.15 \mathrm{mM}$ calculated by Rajagopalan \& Handler (1964) for this compound using rabbit liver aldehyde oxidase. However, it has been noted previously that the substrate specificity of the lapine liver enzyme is quite different to that of guinea pig and human aldehyde oxidase (Johns, 1967; Beedham et al., 1987a; Beedham et al., 1990).

In general, hydroxy-, and methoxy-benzaldehydes are more efficient substrates for guinea pig liver aldehyde oxidase (Table 2) than most heterocyclic substrates such as phthalazine $\left(K_{\mathrm{m}}=0.052 \mathrm{mM}, V_{\max }=0.542 \mu \mathrm{mol} / \mathrm{min}\right.$ per $\mathrm{mg}$ protein) (Beedham et al., 1990), quinazoline $\left(K_{\mathrm{m}}=0.031 \mathrm{mM}, V_{\max }=0.639\right.$ $\mu \mathrm{mol} / \mathrm{min}$ per $\mathrm{mg}$ protein) (Critchley, 1989) and $N$-methylquinolinium salts $\left(K_{\mathrm{m}}=0.05\right.$ $\mathrm{mM}$ ) (Taylor et al., 1984). This is due to higher affinities of the enzyme rather than higher $V_{\max }$ values. $K_{\mathrm{m}}$ values for heterocyclic substrates tend to range from $0.02 \mathrm{mM}$ to $0.01 \mathrm{mM}$, whereas those for these aromatic aldehydes are between $0.004 \mathrm{mM}$ to $0.03 \mathrm{mM}$. This may be due to methodological differences, for example the use of different electron acceptors. The oxidation rates of the aldehydes in this study were measured by using molecular oxygen as the electron acceptor whereas those of heterocyclic substrates with an artificial electron acceptor, ferricyanide.
Reoxidation of aldehyde oxidase occurs at different redox centers depending on the electron acceptor used. Oxygen reacts at the flavin center (FAD) of aldehyde oxidase, whereas ferricyanide acts as the oxidizing substrate at an iron/sulphur center of the enzyme (Coughlan \& Ni Fhaolain, 1979). However, it was possible to determine the kinetic constants for one of the aldehydes, 4-hydroxy-3-methoxybenzaldehyde, using the same enzyme preparation with either molecular oxygen or ferricyanide as electron acceptors. The $K_{\mathrm{m}}$ and $V_{\max }$ values calculated for this compound were $0.029 \mathrm{mM}$ and 0.45 $\mu \mathrm{mol} / \mathrm{min}$ per mg protein, respectively, when molecular oxygen was used as the electron acceptor, whereas in the presence of ferricyanide the values were $0.035 \mathrm{mM}$ and 0.41 $\mu \mathrm{mol} / \mathrm{min}$ per $\mathrm{mg}$ protein, respectively. This indicates that, for this group of compounds, the choice of electron acceptor does not have a significant effect on the kinetic constants. Similarly, uncharged substrates such as phthalazine and quinoline show only small variations in $K_{\mathrm{m}}$ values with different electron acceptors (Taylor et al., 1984).

In contrast to most of the other aldehydes, 3-hydroxy-4-methoxy-, and 3,4-dihydroxybenzaldehydes did not react with guinea pig liver aldehyde oxidase, although the other two di-substituted benzaldehydes, 4-hydroxy3-methoxy-, and 3,4-dimethoxy-benzaldehydes, were found to be reasonable substrates (Table 2). These compounds were found to be inhibitors of aldehyde oxidase from guinea pig liver (Panoutsopoulos, 1994; Beedham et al., 1995b).

\section{3-Hydroxy-4-methoxy-, and 3,4-dihydroxy- benzaldehydes as inhibitors of aldehyde oxidation by guinea pig liver aldehyde oxidase}

3-Hydroxy-4-methoxy-, and 3,4-dihydroxybenzaldehydes were tested as inhibitors of 2-hydroxybenzaldehyde oxidation (Table 3). 
Table 3. The inhibitory effect of 3,4-dihydroxy-, and 3-hydroxy-4-methoxy-benzaldehydes on guinea pig liver aldehyde oxidase with 2-hydroxybenzaldehyde as substrate.

\begin{tabular}{lll}
\hline Inhibitors & $\begin{array}{l}\text { Inhibitor concentration } \\
(\mathrm{mM})\end{array}$ & $\begin{array}{l}\text { Inhibition of 2-hydroxy-benzaldehyde } \\
\text { oxidation* (\%) }\end{array}$ \\
\hline 3-Hydroxy-4-methoxybenzaldehyde & 0.1 & 87 \\
3,4-Dihydroxybenzaldehyde & 0.1 & 87 \\
\hline
\end{tabular}

${ }^{*}$ Concentration of 2-hydroxybenzaldehyde $=0.1 \mathrm{mM}$

3-Hydroxy-4-methoxybenzaldehyde (Fig. 3) and 3,4-dihydroxy-benzaldehyde (Fig. 4) were both potent competitive inhibitors of 2-hydroxybenzaldehyde oxidation by aldehyde oxidase with $K_{\mathrm{i}}$ values of $6.64 \times 10^{-4}$ $\mathrm{mM}(\mathrm{n}=2)$ and $1.57 \times 10^{-4} \mathrm{mM}(\mathrm{n}=2)$, respectively.

Johnson et al. (1985) reported an inhibitory effect of hydralazine on the oxidation of purine by rabbit, guinea pig and baboon liver aldehyde oxidase. Critchley (1989) tested the ef-

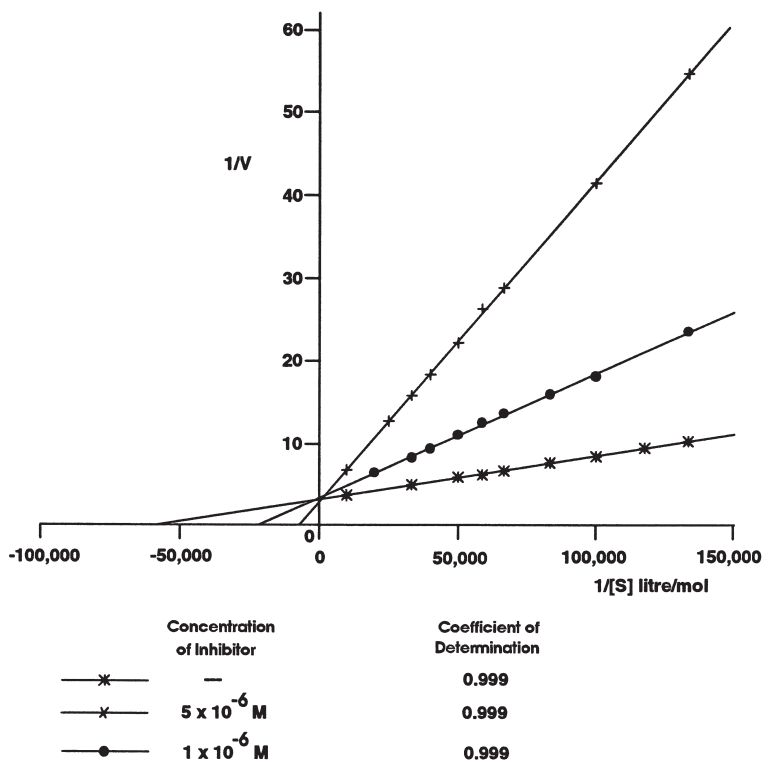

Figure 3. Lineweaver-Burk plots for determination of the inhibitor constant for 3-hydroxy-4-methoxybenzaldehyde (isovanillin) with guinea pig liver aldehyde oxidase.

The rate of oxidation of at least ten concentrations of 2-hydroxybenzaldehyde was monitored in the presence or absence of two concentrations of the inhibitor, [I], and measured at $37^{\circ} \mathrm{C}$ with molecular oxygen as electron acceptor at $255 \mathrm{~nm}$. fect of hydralazine administration on guinea pig liver aldehyde oxidase. He found that the oxidation rate of phthalazine, phenanthridine and carbazeran was reduced to less than half that of control animals when the enzyme was prepared from hydralazine $(10 \mathrm{mg} / \mathrm{kg}$ per day) treated guinea pigs. However, when xanthine was used as substrate there was no reduction in the oxidation rate. These results suggest that hydralazine acts as a potent inhibitor of aldehyde oxidase in vivo and in vitro, but does not have any inhibitory effect on xanthine oxidase.

\section{Inhibition of aldehyde oxidase by amines and catechols}

As inhibition of aldehyde oxidase appeared to be related to the presence of 3-hydroxy-, or 3,4-dihydroxy-substituents in the benzaldehydes, a number of amines and catechols were tested with guinea pig liver aldehyde oxidase (Table 4). However, the same benzaldehyde concentration could not always be employed in each case because (a) difficulties were encountered with measuring out small amounts of liquid and (b) the cumulative absorbance of both benzaldehyde and some of the inhibitors made spectrophotometric readings not possible.

Of all the compounds tested, 2-phenylethylamine, at $1 \mathrm{mM}$, was the weakest inhibitor showing only a marginal effect on benzaldehyde oxidation. 4-Hydroxy-3-methoxy-2phenylethylamine was also found to be relatively ineffective as an inhibitor but 
3,4-dimethoxy-2-phenylethylamine inhibited benzaldehyde oxidation to a great extent.

The catecholamines, 3,4-dihydroxy-2-phenylethylamine (dopamine), 3,4-dihydroxy-phenylethanolamine (noradrenaline) and catechol (1,2-dihydroxybenzene), had the greatest effect on benzaldehyde oxidation. Thus at equimolar concentrations, noradrenaline $(0.1 \mathrm{mM})$ inhibited the oxidation by $90 \%$. As unsubstituted catechol inhibited
Alton, 1968), was only a weak inhibitor of aldehyde oxidase.

Inhibition studies of 2-hydroxybenzaldehyde oxidation showed dopamine to be a potent uncompetitive inhibitor of aldehyde oxidase with a $K_{\mathrm{i}}$ value of $0.0071 \mathrm{mM}$ (Fig. 5).

Uncompetitive inhibition, as exhibited towards aldehyde oxidase, normally implies reaction of the inhibitor with the enzyme-substrate complex [ES] to produce a dead end

Table 4. The inhibitory effect of catechols and amines on guinea pig liver aldehyde oxidase with benzaldehyde as substrate.

\begin{tabular}{lll}
\hline Inhibitors & $\begin{array}{l}\text { Inhibitor concentration } \\
(\mathrm{mM})\end{array}$ & $\begin{array}{l}\text { Inhibition of benzaldehyde } \\
\text { oxidation (\%) }\end{array}$ \\
\hline 2-Phenylethylamine* & 1 & 10 \\
& 0.1 & 10 \\
4-Hydroxy-3-methoxy-2-phenylethylamine* & 1 & 55 \\
& 0.1 & 21 \\
3,4-Dimethoxy-2-phenylethylamine* & 1 & 100 \\
& 0.1 & 48 \\
Dopamine $^{* *}$ & 1 & 100 \\
Noradrenaline $^{* *}$ & 0.1 & 59 \\
Catechol $^{* *}$ & 1 & 100 \\
& 0.1 & 90 \\
L-Dopa $^{* *}$ & 1 & 98 \\
DOPAC $^{* * *}$ & 0.1 & 64 \\
\hline
\end{tabular}

*Benzaldehyde concentration $=0.04 \mathrm{mM} ;{ }^{* *}$ Benzaldehyde concentration $=0.1 \mathrm{mM} ;{ }^{* * *}$ Benzaldehyde concentration $=0.8 \mathrm{mM}$.

benzaldehyde oxidation to a similar extent as that of dopamine, it would appear that the inhibition may be caused by the presence of a catechol group, rather than of the ethylamine side chain. This is supported by the results obtained with 2-phenylethylamine. L-DOPA appeared to be a less effective inhibitor of aldehyde oxidase than dopamine, catechol and noradrenaline. 3,4-Dihydroxyphenylacetic acid (DOPAC), one of the major metabolites of dopamine (Williams et al., 1960; Goodall \& product [ESI], the inhibitor preventing the regeneration of the enzyme in a form capable of reacting directly with the substrate.

\section{Inhibition of aldehyde oxidase by substi- tuted catechols}

In order to determine whether the inhibition observed with 3-hydroxy-4-methoxybenzaldehyde and 3,4-dihydroxybenzaldehyde, noradrenaline and dopamine was a general 


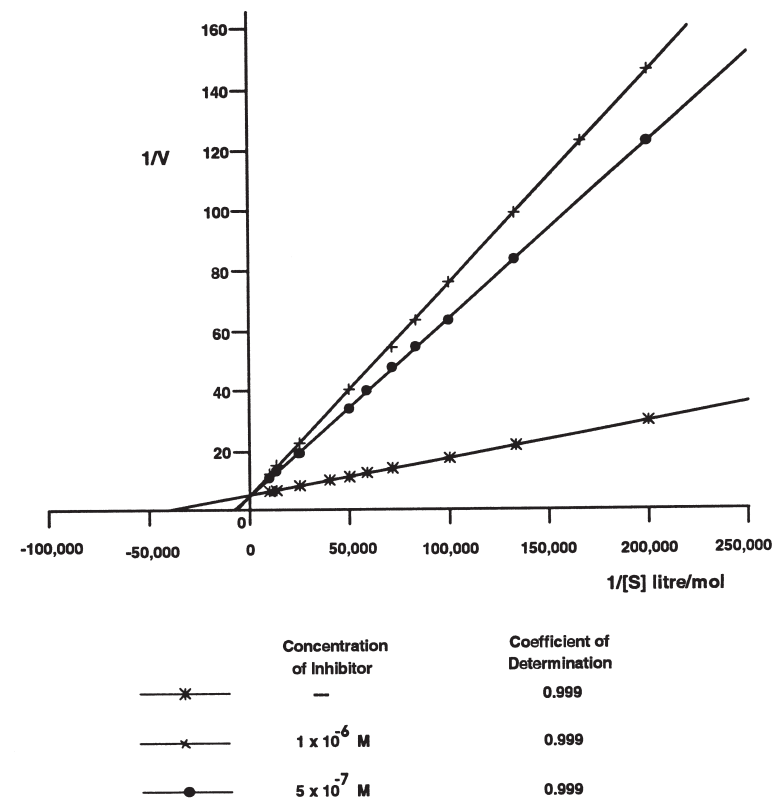

Figure 4. Lineweaver-Burk plots for determination of the inhibitor constant for 3,4-dihydroxybenzaldehyde (protocatechuic aldehyde) with guinea pig liver aldehyde oxidase.

The rate of oxidation of at least ten concentrations of 2-hydroxy-benzaldehyde was monitored in the presence or absence of two concentrations of the inhibitor, [I], and measured at $37^{\circ} \mathrm{C}$ with $\mathrm{O}_{2}$ as electron acceptor at $255 \mathrm{~nm}$.

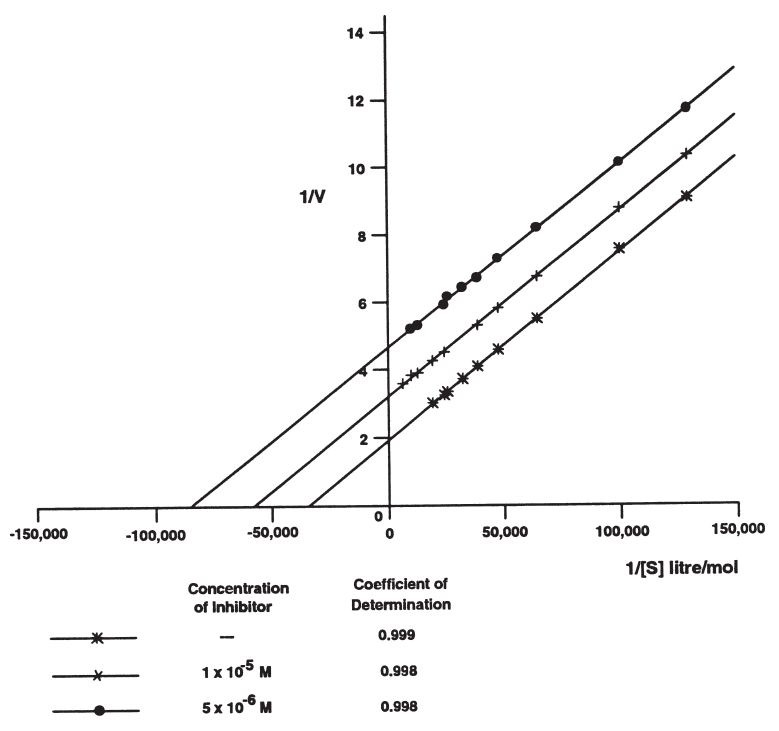

Figure 5. Lineweaver-Burk plots for determination of the inhibitor constant for dopamine with guinea pig liver aldehyde oxidase.

The rate of oxidation of at least ten concentrations of 2-hydroxybenzaldehyde was monitored in the presence or absence of two concentrations of the inhibitor, [I], and measured at $37^{\circ} \mathrm{C}$ with molecular oxygen as electron acceptor at $255 \mathrm{~nm}$.

Table 5. The inhibitory effect of substituted catechols on guinea pig liver aldehyde oxidase with phenanthridine and $N$-methylphthalazinium chloride as substrates.

\begin{tabular}{lllc}
\hline \multirow{2}{*}{ Inhibitors } & $\begin{array}{l}\text { Inhibitor concen- } \\
\text { tration }(\mathrm{mM})\end{array}$ & $\begin{array}{l}\text { Inhibition of substrate oxidation (\%) } \\
\text { Phenanthridine }\end{array}$ & $N_{\text {-methylphthalazinium }}^{* *}$ \\
\hline \multirow{2}{*}{ 3-Hydroxy-4-methoxybenzal- } & 0.1 & 87 & 85 \\
dehyde & 0.01 & 17 & 34 \\
& 0.001 & 0 & 20 \\
3,4-Dihydroxybenzaldehyde & 0.1 & 96 & $\S$ \\
& 0.01 & 50 & 76 \\
& 0.001 & 3 & 64 \\
Noradrenaline & 1 & 91 & $\S$ \\
& 0.1 & 51 & 95 \\
& 0.01 & 17 & 32 \\
& 0.001 & 10 & 6 \\
Dopamine & 0.1 & 80 & 93 \\
& 0.01 & 19 & 32 \\
\hline
\end{tabular}

${ }^{*}$ Phenanthridine concentration $=0.05 \mathrm{mM}\left(\lambda_{\max }=322 \mathrm{~nm}\right) ;{ }^{* *} N$-Methylphthalazinium concentration $=0.05 \mathrm{mM}\left(\lambda_{\max }=320\right.$ $\mathrm{nm}$ ); molecular oxygen was used as an acceptor. §, Combined absorbance too high. 
property of these compounds, or peculiar to the oxidation of aldehydes, these compounds were also tested against two N-heterocyclic substrates, namely phenanthridine and $N$-methylphthalazinium chloride.

These two heterocyclic substrates were chosen for three reasons. Firstly, both phenanthridine (Stubley \& Stell, 1980; Beedham, 1987) and $N$-methylphthalazinium (Critchley, 1989; Beedham et al., 1990) are relatively specific substrates for aldehyde oxidase. Secondly, phenanthridine is a typical uncharged heterocycle, whereas $N$-methylphthalazinium is a charged quaternary compound and these may bind at different sites. Thirdly, their use
(Table 3). 3,4-Dihydroxybenzaldehyde inhibited aldehyde oxidase with phenanthridine as substrate and, particularly, $N$-methylphthalazinium (Table 5) to a greater extent than that of 2-hydroxybenzaldehyde (Table 3).

The percentage inhibition of $\mathrm{N}$-methylphthalazinium and benzaldehyde oxidations by noradrenaline were of similar magnitude, whereas the effect upon phenanthridine oxidation was less marked. Dopamine appeared to be an even more effective inhibitor of phenanthridine and $N$-methylphthalazinium oxidation than of benzaldehyde.

These results showed that 3-hydroxy-4-methoxybenzaldehyde, 3,4-dihydroxybenzalde-

Table 6. Kinetic constants for the oxidation of substituted benzaldehydes by bovine milk xanthine oxidase.

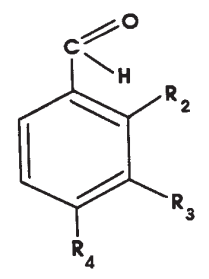

\begin{tabular}{ccclll}
\hline $\mathrm{R}_{2}$ & $\begin{array}{c}\text { Substituent } \\
\mathrm{R}_{3}\end{array}$ & $\mathrm{R}_{4}$ & $\begin{array}{l}K_{\mathrm{m}}{ }^{*} \\
(\mathrm{mM})\end{array}$ & $\begin{array}{l}V_{\max } \\
(\mu \mathrm{mol} / \mathrm{min} \text { per mg) }\end{array}$ & $\begin{array}{l}K_{\mathrm{s}}=\left(V_{\max } / K_{\mathrm{m}}\right) \\
(\mathrm{ml} / \mathrm{min} \text { per mg })\end{array}$ \\
\hline $\mathrm{H}$ & $\mathrm{H}$ & $\mathrm{H}$ & 0.3 & 0.17 & 0.5 \\
$\mathrm{OH}$ & $\mathrm{H}$ & $\mathrm{H}$ & 0.19 & 0.67 & 3.5 \\
$\mathrm{H}$ & $\mathrm{OH}$ & $\mathrm{H}$ & 0.18 & 0.95 & 5.4 \\
$\mathrm{H}$ & $\mathrm{H}$ & $\mathrm{OH}$ & 0.17 & 3.29 & 19.8 \\
$\mathrm{OCH}_{3}$ & $\mathrm{H}$ & $\mathrm{H}$ & 0.19 & 0.10 & 0.5 \\
$\mathrm{H}$ & $\mathrm{OCH}_{3}$ & $\mathrm{H}$ & 0.17 & 0.59 & 3.4 \\
$\mathrm{H}$ & $\mathrm{H}$ & $\mathrm{OCH}_{3}$ & 0.17 & 0.17 & 1.0 \\
$\mathrm{H}$ & $\mathrm{OH}$ & $\mathrm{OH}$ & 0.039 & 0.40 & 10.0 \\
$\mathrm{H}$ & $\mathrm{OH}$ & $\mathrm{OCH}_{3}$ & 0.18 & 0.95 & 5.3 \\
$\mathrm{H}$ & $\mathrm{OCH}_{3}$ & $\mathrm{OH}_{3}$ & 0.12 & 0.27 & 1.3 \\
$\mathrm{H}$ & $\mathrm{OCH}_{3}$ & $\mathrm{OCH}_{3}$ & 0.68 & 0.22 & 0.3 \\
\hline
\end{tabular}

The oxidation rates of substituted benzaldehydes by xanthine oxidase were measured spectrophotometrically at $37^{\circ} \mathrm{C}$ with molecular oxygen as an acceptor. For details see Materials and Methods. All correlation coefficients $(r)>0.998 ;{ }^{*} \mathrm{n}=2$.

facilitates the experimental conditions, since substrate and product have different UV spectra making spectrophotometric measurements under oxygen possible.

3-Hydroxy-4-methoxybenzaldehyde $\quad(0.1$ $\mathrm{mM}$ ) had a similar inhibitory effect on the oxidation of phenanthridine, $N$-methylphthalazinium (Table 5) and 2-hydroxybenzaldehyde hyde, noradrenaline and dopamine not only inhibit aldehyde oxidase, but also the oxidation of charged and uncharged heterocycles. This assumption is also supported by the inhibition of phthalazine and 4-hydroxy-3-methoxybenzaldehyde (vanillin) oxidation by aldehyde oxidase, monitored by HPLC (Panoutsopoulos, 1994). 
Kinetic constants for the oxidation of substituted benzaldehydes with bovine milk xanthine oxidase

In this study, all the compounds examined were found to be substrates for bovine milk xanthine oxidase. $K_{\mathrm{m}}$ values for these benzaldehydes were at least ten-fold higher than with aldehyde oxidase, but with the exception of 3,4-dihydroxybenzaldehyde, they did not vary significantly (Table 6 ). The lowest $K_{\mathrm{m}}$ value was obtained with 3,4-dihydroxybenzaldehyde but this was still 5-10 fold higher than that of xanthine $\left(K_{\mathrm{m}}=\right.$ 0.004-0.008 mM) (Krenitsky et al., 1986; Spector et al., 1986).

Oxidation rates varied to a greater extent between the compounds examined with the highest $V_{\max }$ value being that of 4-hydroxybenzaldehyde which was thus the best substrate in term of substrate efficiency $\left(K_{\mathrm{S}}\right)$. The monosubstituted hydroxy-benzaldehydes gave higher $V_{\max }$ values than the analogous monosubstituted methoxy-derivatives.

Whilst 3,4-dihydroxy-, and 3-hydroxy-4-methoxy-benzaldehydes are potent inhibitors of aldehyde oxidase in vitro, they do not appear to exert a similar inhibitory effect upon xanthine oxidase. Therefore, it would appear that the presence of a 3-hydroxy group did not hinder the oxidation reaction catalysed by bovine milk xanthine oxidase.

Krenitsky et al. (1986) found benzaldehyde to be a relatively poor substrate for human liver xanthine oxidase with a low affinity for the enzyme $\left(K_{\mathrm{m}}=0.93 \mathrm{mM}\right)$. This value was in a similar range to the one reported in the present studies using bovine milk xanthine oxidase.

Oxidation of 2-hydroxybenzaldehyde has also been reported by Morpeth (1983) $\left(K_{\mathrm{m}}=1\right.$ $\mathrm{mM}$ ) for bovine milk xanthine oxidase. This $K_{\mathrm{m}}$ value is five-fold higher than that reported in this study. However, this discrepancy is probably due to the different experimental conditions used. In addition, Morpeth (1983) found the $K_{\mathrm{m}}$ for 2,5-dihydroxybenzaldehyde with bovine milk xanthine oxidase to be $0.068 \mathrm{mM}$, whereas Xia et al. (1999) found this substrate to have a $K_{\mathrm{m}}$ value of $0.004 \mathrm{mM}$ at $\mathrm{pH}$ 7.0.

Purines, which are excellent substrates for xanthine oxidase, have $K_{\mathrm{m}}$ values in the order of $10^{-4}$ to $10^{-3} \mathrm{mM}$ (Krenitsky et al., 1986). Oxidation rates of substituted purines are also significantly higher than those of benzaldehydes making the latter group of compounds relatively weak substrates. Although some of these compounds were transformed as rapidly as xanthine their high $K_{\mathrm{m}}$ values make them relatively inefficient substrates of xanthine oxidase.

\section{Inhibitors of xanthine oxidase}

Noradrenaline and dopamine were also tested as inhibitors of xanthine oxidase. In contrast to the results obtained with aldehyde oxidase, they were found to be very weak inhibitors of benzaldehyde oxidation catalysed by xanthine oxidase (Table 7).

Table 7. The inhibitory effect of amines on benzaldehyde oxidation by bovine milk xanthine oxidase.

\begin{tabular}{lll}
\hline Inhibitors & Inhibitor concentration $(\mathrm{mM})$ & $\begin{array}{l}\text { Inhibition of benzaldehyde oxidation* } \\
(\%)\end{array}$ \\
\hline \multirow{2}{*}{ Noradrenaline } & 1 & 30 \\
& 0.1 & 15 \\
Dopamine & 1 & 23 \\
& 0.1 & 23 \\
\hline
\end{tabular}

${ }^{*}$ Concentration of benzaldehyde $=0.1 \mathrm{mM}$ 


\section{CONCLUSIONS}

The two enzymes used for the spectrophotometric determination of the kinetic constants were guinea pig liver aldehyde oxidase and bovine milk xanthine oxidase. These two enzymes were chosen as they have similar substrate specificity to human liver aldehyde (Beedham et al., 1987a; Beedham et al., 1990) and xanthine (Krenitsky et al., 1986) oxidases.

The kinetic constants have indicated that the hydroxy-, and methoxy-benzaldehydes are excellent substrates for aldehyde oxidase but less efficient substrates for xanthine oxidase. Although the oxidation rates for some of the compounds with xanthine oxidase are quite comparable to those for xanthine, the high $K_{\mathrm{m}}$ values make these compounds relatively poor substrates for the enzyme.

From these studies it appears, therefore, that the activity of aldehyde oxidase may be a significant factor in the oxidation of aromatic aldehydes either generated from biogenic amines, or present in foods. They occur as natural (flavouring) constituents in a variety of foods and food components and are also widely used as food additives (Coughlan, 1980; Feron et al., 1991).

\section{R E F E R E N C E S}

Beedham C. (1985) Molybdenum hydroxylases as drug-metabolizing enzymes. Drug Met Rev.; 16: 119-56.

Beedham C. (1987) Molybdenum hydroxylases: biological distribution and substrate-inhibitor specificity. Prog Med Chem.; 24: 85-127.

Beedham C, Bruce SE, Critchley DJ, Al-Tayib Y, Rance DJ. (1987a) Species variation in hepatic aldehyde oxidase activity. Eur $J$ Drug Metab Pharmacokinet.; 12: 307-10.

Beedham C, Bruce SE, Rance DJ. (1987b) Tissue distribution of the molybdenum hydroxylases, aldehyde oxidase and xanthine oxidase, in male and female guinea pigs. Eur J Drug Metab Pharmacokinet.; 12: 303-6.

Beedham C, Bruce SE, Critchley DJ, Rance DJ. (1990) 1-Substituted phthalazines as probes of the substrate-binding site of mammalian molybdenum hydroxylases. Biochem Pharmacol.; 39: 1213-21.

Beedham C, Critchley DJP, Rance DJ. (1995a) Substrate specificity of human liver aldehyde oxidase toward substituted quinazolines and phthalazines: a comparison with hepatic enzyme from guinea pig, rabbit and baboon. Arch Biochem Biophys.; 319: 481-90.

Beedham C, Peet CF, Panoutsopoulos GI, Carter H, Smith JA. (1995b) Role of aldehyde oxidase in biogenic amine metabolism. Prog Brain Res.; 106: 345-53.

Booth VH. (1938) The specificity of xanthine oxidase. Biochem J.; 32: 494-502.

Bradford MM. (1976) A rapid and sensitive method for the quantification of microgram quantities of protein utilizing the principle of protein-dye binding. Anal Biochem.; 72: 248-54.

Bruder G, Heid H, Jarasch ED, Keenan TW, Mather IH. (1982) Characteristics of membrane-bound and soluble forms of xanthine oxidase from milk and endothelial cells of capillaries. Biochim Biophys Acta.; 701: 357-69.

Coughlan, MP. (1980) In Molybdenum and Molybdenum Containing Enzymes. Coughlan MP, ed. Pergamon Press, Oxford.

Coughlan MP, Ni Fhaolain I. (1979) On the sites of interaction of oxidizing substrates with molybdenum iron/sulphur flavin hydroxylases. Proc $R$ Irish Acad.; 79B: $169-75$.

Critchley DJP. (1989) In Diazanaphthalenes as Probes of Molybdenum Hydroxylase Activity. $\mathrm{PhD}$ Thesis, University of Bradford, Bradford, UK.

Critchley DJ, Rance DJ, Beedham C. (1992) Subcellular localization of guinea pig hepatic molybdenum hydroxylases. Biochem Biophys Res Commun.; 185: 54-9. 
Dellarco VL. (1988) A mutagenicity assessment of acetaldehyde. Mutat Res.; 195: 1-20.

Feron VJ, Til HP, de Vrijer F, Woutersen RA, Cassee FR, van Bladeren PJ. (1991) Aldehydes: occurrence, carcinogenic potential, mechanism of action and risk assessment. Mutat Res.; 259: 363-85.

Goodall McC, Alton H. (1968) Metabolism of 3-hydroxytyramine (dopamine) in human subjects. Biochem Pharmacol.; 17: 905-14.

Gordon AH, Green DE, Subrahmanyan V. (1940) Liver aldehyde oxidase. Biochem J.; 34: 764-74.

Hazen SL, Hsu FF, d'Avignon A, Heinecke JW. (1998) Human neutrophils employ myeloperoxidase to convert $\alpha$-amino acids to a battery of reactive aldehydes: a pathway for aldehyde generation at sites of inflammation. Biochemistry.; 37: 6864-73.

Johns DG. (1967) Human liver aldehyde oxidase: Differential inhibition of oxidation of charged and uncharged substrates. $J$ Clin Invest.; 46: 1492-505.

Johnson C, Stubley-Beedham C, Stell JGP. (1985) Hydralazine: A potent inhibitor of aldehyde oxidase activity in vitro and in vivo. Biochem Pharmacol.; 34: 4251-6.

Krenitsky TA, Neil SM, Elion GB, Hitchings GH. (1972) A comparison of the specificities of xanthine oxidase and aldehyde oxidase. Arch Biochem Biophys.; 150: 585-99.

Krenitsky TA, Spector T, Hall WW. (1986) Xanthine oxidase from human liver: purification and characterization. Arch Biochem Biophys.; 247: 108-19.

Lindahl R. (1992) Aldehyde dehydrogenases and their role in carcinogenesis. Crit Rev Biochem Mol Biol.; 27: 283-335.

Ma TH, Harris MM. (1988) Review of the genotoxicity of formaldehyde. Mutat Res.; 196: $37-59$.

Modi VV, Owen EC, Proudfoot R. (1959) Species differences in the occurrence of xanthine oxidase in milk. Proc Nutr Soc.; 18: i.
Morpeth FF. (1983) Studies on the specificity toward aldehyde substrates and steady-state kinetics of xanthine oxidase. Biochim Biophys Acta.; 744: 328-34.

Panoutsopoulos GI. (1994) In Hepatic Oxidation of Aromatic Aldehydes. PhD Thesis, University of Bradford, Bradford, UK.

Pelsy G, Klibanov AM. (1983) Remarkable positional (regio)specificity of xanthine oxidase and some dehydrogenases in the reactions with substituted benzaldehydes. Biochim Biophys Acta.; 742: 352-7.

Rajagopalan KV, Handler P. (1964) Hepatic aldehyde oxidase: The substrate-binding site. $J$ Biol Chem.; 239: 2027-35.

Sasaki K, Hosoya R, Wang YM, Raulston GL. (1983) Formation and disposition of 7-hydroxymethotrexate in rabbits. Biochem Pharmacol.; 32: 503-7.

Smith RF, Otremba ED. (1962) The preparation and properties of some 1,2-dihydroxyphthalazine derivatives. $J \mathrm{Org}$ Chem.; 27: 879-82.

Spector T, Hall WW, Krenitsky TA. (1986) Human and bovine xanthine oxidases: Inhibition studies with oxipurinol. Biochem Pharmacol.; 35: 3109-14.

Stubley C, Stell JGP. (1980) Investigation of the substrate-binding site of aldehyde oxidase. $J$ Pharm Pharmac.; 32: 51P.

Taylor SM, Stubley-Beedham C, Stell JGP. (1984) Simultaneous formation of 2- and 4-quinolones from quinolinium cations catalysed by aldehyde oxidase. Biochem J.; 220: $67-74$.

Washio K, Makaya O, Sasaki H, Nishida K, Nakamura J, Shibasaki J. (1993) A new aspect of tolbutamide metabolism in the rabbit: the role of 1-butyl-3-(p-formylphenyl) sulphonylurea. J Pharm Pharmacol.; 45: 231-3.

Wilkof CA, Korus RA, Crawford DL, Pometto III AL. (1984) Enzymic oxidation of aromatic aldehydes. Biotechnol Bioeng Symp.; 14: 419-23. 
Williams CM, Bubuscio AA, Watson R. (1960) In vivo alteration of the pathways of dopamine metabolism. Am J Physiol.; 199: $722-6$.

Wurzinger KH, Hartenstein R. (1974) Phylogeny and correlations of aldehyde oxidase, xanthine oxidase, xanthine dehydrogenase and peroxidase in animal tissues. Comp Biochem Physiol.; 49B: 171-85.

Xia M, Dempski R, Hille R. (1999) The reductive half-reaction of xanthine oxidase. $J$ Biol Chem.; 274: 3323-30. 